\title{
Treatment of the so-called idiopathic scoliosis by physiotherapy - incorrect or correct - examples of both group of children
}

Tomasz Karski $^{1 *}$, Jacek Karski

From 11th International Conference on Conservative Management of Spinal Deformities - SOSORT 2014

Annual Meeting

Wiesbaden, Germany. 8-10 May 2014

\section{Introduction}

The biomechanical aetiology of so-called idiopathic scoliosis called AIS is described in years 1995 - 2007 (T. Karski) and presented since 2002 in many Congresses and Symposia.

\section{Material}

In 2012 the whole material gathered 1950 cases. Patients were 2 to 60 years old.

Explanation of biomechanical aetiology of scoliosis in point

1. "Syndrome of contractures" [SofC] (Siebenersyndrom) according to Prof.Hans Mau.

2. Asymmetry in movement of hips connected with SofC. Limited movement of the right hip.

3. Influence on spine comes by walking (gait) and because of habit of permanent standing 'at ease' on the right leg.

New classification as input for physiotherapy

There are three groups and four types (T. Karski 2001 - 2004).

1) "S" I etiopathological (epg) scoliosis. Influenced by the "gait" and the permanent "standing at ease on the right leg".

2)

a. 2A/ "C" II/A epg scoliosis - Influenced by the permanent "standing at ease on the right leg".

b. 2B/ "S" II/B epg scoliosis - Influenced by the permanent "standing at ease on the right leg", plus - laxity of joints or/and incorrect exercises in previous treatment.
3) "I" III epg scoliosis. Influenced by the "gait" only.

\section{Physiotherapy}

All previous extensions, its mean "muscles strengthening exercises" were incorrect and caused only bigger curves and made the spine more stiff. All stretching exercises are proper for treatment and for prophylaxis

\section{Conclusions}

1. All scientists and all Institutions engaged with scoliosis should learn about "biomechanical reasons in development of scoliosis".

2. All orthopaedic surgeons, rehabilitations and physiotherapies should be introduced to the new conception of treatment and of causal prophylaxis in children with so-called idiopathic scoliosis using the own material.

\section{Authors' details}

${ }^{1}$ Vincent Pol University, Lublin, Poland. ²Department of Paediatric Orthopaedic and Rehabilitation, Medical University, Lublin, Poland.

Published: 4 December 2014

\section{Reference}

1. [http://www.ortopedia.karski.lublin.pl].

doi:10.1186/1748-7161-9-S1-P10

Cite this article as: Karski and Karski: Treatment of the so-called

idiopathic scoliosis by physiotherapy - incorrect or correct - examples

of both group of children. Scoliosis 2014 9(Suppl 1):P10.

Vincent Pol University, Lublin, Poland

Full list of author information is available at the end of the article 